\title{
ASPECTOS ATUAIS DE ENFERMAGEM NO CONTROLE E TRATAMENTO DA INFECÇÃO HOSPITALAR
}

\author{
Maria Lúcia Pimentel de Assis Moura*
}

\begin{tabular}{l|l}
$\longdiv { R B E n } / 0 9$ \\
\hline
\end{tabular}

MOURA, M.L.P.A. - Aspectos atuais de enfermagem no controle e tratamento de infecçāo hospitalar. Rev. Bras. Enf.; DF, 29 : 75-84, 1976.

\section{I - INTRODUĢA:}

"As infecçōes hospitalares, segundo estimativas consideradas otimistas, matam mais de $\mathbf{5 0}$ mil pessoas por ano no Brasil". (O jornal "O Estado de São Paulo").

Pela gravidade do problema é necessário institutir-se no Hospital, medidas de controle e tratamento da infecção hospitalar, com a finalidade primordial de zelar pelo bem-estar do paciente, conseguindo a diminuição da permanência do mesmo no hospital, e conseqüentemente a diminuição do custo/paciente.

A aquisição de doença infecciosa pela pupulação hospitalizada é decorrente de vários fatores, tais como:

- agressão cirúrgica a que são submetidos os pacientes, abrindo-se vias de penetração para os germens, e quanto maior a agressão cirúrgica e o tempo de exposição do paciente ao ato ci- rúrgico, maior a probabilidade do paciente em adquirir uma infecção;

- o uso intensivo e prolongado de equipamentos de respiração assistida, de difícil limpeza e descontaminação, e que levam os germens até o sistema respiratório do paciente, através dos aparelhos;

- o grande número de cateterismos vesicais a que os doentes são submetidos;

- o grande número de cateterismos venosos, para hidratação, controle de pressão venosa central e alimentação parenteral;

- os exames radiológicos, cada vez mais sofisticados, exigindo cateterizaçōes de veias para infusōes de contrastes;

- a presença de doentes infectados no hospital;

- a quimioterapia, os prolongados tratamentos antibióticos e corticoterápicos e a sobrevida de doentes em más condiçōes nas Unidades de Tratamento Intensivo.

- Chefe do Serviço de Enfermagem do Hospital "9 de julho" S/A. 
MOURA, M.L.P.A. - Aspectos atuais de enfermagem no controle e tratamento de infecçăo hospitalar. Rev. Bras. En?.; DF, 29 : 75-84, 1976.

\section{II - CONCEITUAÇAO:}

Consideramos I n f e c çā o Hospitalar aquela infecção diagnosticada clinicamente e que teve seu início após 48 horas da internação do paciente. Outrossim, consideramos também como Infecção Hospitalar aquela infecção surgida após instrumentação endoscópica ou intervenção cirúrgica.

As fontes de infecção hospitalar podem ser:

- Endógenas: quando o agente infeccloso origina-se do próprio paciente;

- Exógena: quando o agente infeccioso procede do exterior.

\section{III - ETIOLOGIA DAS INFECÇOEES HOSPITALARES:}

Os agentes mais comumente encontrados no meio hospitalar, causadores diretos ou indiretos das infecçōes, sāo:

- Staphylococcus aureus: (coagulase positiva) - é um dos principais responsáveis pelas infecçōes pós-operatórias das incisōes cirúrgicas, infecçōes cutâneas localizadas ou disseminadas, infecçōes do aparelho respiratório. Comumente é encontrado nas fossas nasais, mãos, roupas usadas, ar, pisos e outros.

- Enterobactérias: sob essa denominação compreende-se um grande grupo de balstonetes gram negativos, não esporulados, sendo os principais:

- Escherichia colí é o grande responsável por surtos epidêmicos de diarréia em Berçários e Unidades pediátricas.

- Klebsiella-enterobacter: é isolado de quase todas as áreas do corpo humano, tais como: pele, nasofaringe de pacientes portadores de infecçōes bronco-pulmonares, gênito-uriárias e intestinais.

- Proteus: encontrado em fezes humanas e de animais, no esgoto, na água poluída e principalmente em matéria orgânica em decomposição.

- Outros bastonetes gram negativos: incluímos nesse grupo um dos principais causadores da disseminação da infecção hospitalar que é a Pseudomona aeruginosa. A Pseudomona aeruginosa é um bastonete gramnegativo, não esporulado, altamente resistente à quase totalidade dos antibióticos atualmente em uso e responsável por um grande número de infecçōes do trato respiratório, urinário e de incisōes cirúrgicas. Desde a descoberta dos antibióticos, a incidência desses microorganismos na infecção hospitalar vem aumentando significativamente, igualando em muitos hospitais as infecçōes causadas por Staphylococus aureus.

Os reservatórios infecciosos desses microorganismos são o esgoto, as águas poluídas e os pacientes. As fontes infecciosas imediatas são as secreçōes patológicas, as soluçōes mal preparadas e o material e instrumental cirúrgico indevidamente esterillzado.

\section{IV - COMISSAO DE INFECÇAO:}

Para tentar-se sanar o problema da Infecçāo Hospitalar, ou melhor, para diminuir-se a incidência e prevalência da mesma no hospital, deverá ser constituída uma "Comissão de Infecção" com a finalidade de:

- analisar e ditar diretrizes para se manter um sistema de registro de infeç̧ōes apresentadas por pacientes dentro do Hospital;

- fazer a investigação epidemíológica das Infecçōes Hospitalares com proposiçōes de medidas de prevenção e controle;

- manter vigilância sobre as técnicas e procedimentos de assepsia em todos 
MOURA, M.L.P.A. - Aspectos atuais de enfermagem no controle e tratamento de infecção hospitalar. Rev. Bras. Enf.; DF, 29 : 75-84, 1976.

os setores do Hospital, visando a proteção dos pacientes;

- manter vigilância sobre a estrutura física e atividades do Hospital, relacionadas com o grau de probabilidade de infecção.

\section{V - METODOS DE CONTROLE DE INFECÇOES:}

Como no nosso Hospital a média de permanência dos pacientes é relativamente pequena, girando em torno de quatro dias para os casos de obstetrícia, de quatro a cinco dias para os casos de cirurgia geral, excetuando-se os casos de neuro-cirurgia e cirurgia cardíaca, que gira em torno de dez dias, instituímos um método de controle preventivo de infecção para os pacientes de maior média de permanência, ou seja, pacientes de neuro-cirurgia e cirurgia cardíaca, assim como para os pacientes situados em áreas consideradas críticas dentro do Hospital, ou sejam: as Unidades de Tratamento Intensivo, o Berçário de recémnascidos de alto-risco, o Centro Cirúrgico e o Centro Obstétrico.

Além desse controle, instituímos o sistema de profilaxia para todos os pacientes que apresentassem qualquer sintomatologia de infecção adquirida no ambiente hospitalar, tais como: deiscência de suturas cirúrgicas, supuraçōes de parede, infecçōes urinárias, diarréias, etc.

Assim é que aos pacientes admitidos na Unidade de neuro-cirurgia e clrurgia cardíaca, são tomados os seguintes cuidados:

- Exames laboratoriais de admissão: hemograma completo, urina Tipo I, e protoparasitológicos.

- Exames radiológicos: Raios $\mathbf{X}$ de campos pleuro-pulmonares.

- Verificação de alguma lesão externa de mucosa, com colheita de material, caso exista lesão.
No Berçário de alto risco e na Unidade de Tratamento Intensivo é colhido, logo no ato de admissão do paciente, secreção de oro-faringe.

Além desses métodos de detecção de infecção trazida pelo próprio paciente, ou seja a infecção endógena, tomamos determinados cuidados para evitarmos a infecção exógena.

Sabemos que, no combate à infecção exógena, a enfermeira é o elemento vital que deverá conhecer e adotar medidas para o controle e combate à infecção.

Em reunião com a Administração do Hospital verificou-se que as técnicas de limpeza hospitalar estavam muito abandonadas e resolveu-se anexar o pessoal de limpeza das áreas de internação e áreas críticas, ao pessoal de enfermagem, com subordinação direta da enfermeira, recebendo dela as orientaçōes que se fizessem necessárias, e sendo por ela supervisionado.

Nesta mesma época padronizamos o uso de produtos de limpeza, assim como do material a ser utilizado, e confeccionamos normas e procedimentos por escrito, exigindo dos serviçais uma técnica mais adequada para o trabalho.

Posteriormente começamos a enfatizar a responsabilidade da enfermeira na verificação dos cuidados de enfermagem dispensados ao paciente, e algumas rotinas especificas foram elaboradas. (Anexo I).

A verificação sistematizada da utilização de material e instrumental nos Centros Cirúrgico e Obstétrico, assim como a verificação das técnicas apropriadas utilizadas na Unidade de Tratamento Intensivo e Berçários, tanto na manipulação de aparelhos como de pacientes, exigiu normas e rotinas apropriadas para cada Unidade. Assim é que instituímos normas e rotinas para controle e tratamento da infecção hospitalar nas seguintes áreas:

- na Unidade de Tratamento Intensivo (Anexo II); 
MOURA, M.L.P.A. - Aspectos atuais de enfermagem no controle e tratamento de infecçåم hospitalar. Rev. Bras. Enf.; DF, 29 : 75-84, 1976.

- na Unidade de Berçários (Anexo III);

- na Unidade de Centro Cirúrgico e Centro Obstétrico (Anexo IV).

Paralelamente sentimos a necessidade de padronização dos testes bacteriológicos a serem efetuados no Centro de Material e Esterilização que confirmassem a esterilização segura dos materiais, assim como o uso de produtos químicos uttlizados para esterilização química a frio (Anexo V).

Juntamente com estes testes, instituímos rotinas para verificação da qualldade da limpeza e desinfecção dos Centros Cirúrgico e Obstétrico (Anexo IV).

Instituímos também em cada Unidade de Internação uma ficha de registro, utilizada pela enfermeira quando a mesma detecta um caso de infecção hospitalar. Para tanto, determinou-se em reunião os critérios para identificação de uma provável infecção e que são:

- Pacientes com febre - acima de $37,8^{\circ} \mathrm{C}$, com exceção dos dois primeiros dias de pós-operatório, onde um pico febril é considerado dentro da normalidade.

- Pacientes com feridas cirúrgicas apresentando supuração ou secreção infectada.

- Lesões de pele contaminada, isto é, apresentando secreçōes infectadas.

- Pacientes com infecçōes urinárias reconhecidas.

- Pacientes com drenos cavitários drenando secreçōes consideradas infectadas.

- Pacientes com diarréia.

Quando um paciente apresenta um ou mais critérios dos acima relacionados, a enfermeira da Unidade preenche uma ficha própria (Anexo VI) faz um pequeno resumo da história do paciente, anota os valores anormais encontrados nos exames laboratoriais, colhe material para cultura e antibiograma, se houver drenagem de secreção, fazendo a respectiva anotação, e anota o uso de antibióticos e corticosteróides que o paciente por ventura esteja fazepdo uso. Essa ficha é posteriormente enviada à Chefia de Enfermagem que a analisará e dará as orientaçōes que se fizerem necessárias.

Mensalmente, as enfermeiras, juntamente com a Chefia de Enfermagem, analisam as fichas de registros, revêem e estudam o prontuário do paciente e verificam as falhas de técnicas de enfermagem encontradas (sondagens vesicais, curativos, técnicas de esterilização, etc.), e a partir dos dados levantados tentam corrigir as erros e aprimorar as técnicas existentes.

Se for comprovado, pelas fichas de registros que o problema é médico (contaminação intra-operatória por falta de assepsia da equipe cirúrgica, uso inadequado de luvas, máscaras, gorros, etc.), o problema é levado ao Diretor Clínico do Hospital, juntamente com todos os dados levantados e são tomadas as medidas que se fizerem necessárias para cada caso.

Nas reuniōes mensais efetuadas são analisadas também os coeficientes de infecção hospitalar existente e verificados os resultados de técnicas introduzidas.

\section{VI - CONCLUSOEES:}

Por ser um problema considerado por nós prioritário, a infecção hospitalar merece destaque especial dentro do programa realizado pelo Serviço de Enfermagem do Hospital "9 de Junho" S/A.

Estando o pessoal de enfermagem em contato contínuo com o paciente nas vinte e quatro horas do dia, cabe a este pessoal zelar pelo bem-estar do paciente, fazendo o controle de infecção, que exige uma contínua e firme prática de 
MOURA, M.L.P.A. - Aspectos atuais de enfermagem no controle e tratamento de infeç̧ão hospitalar. Rev. Bras. Enf.; DF. 29 : 75-84, 1976.

assepsia médica. O pessoal de enfermagem é o responsável direto pelo bom êxito do tratamento instituído, fazendo com que o doente recupere o mais rápido possível a saúde perdida e que possa sair do hospital o mais breve possível.

\section{REFERENCIAS BIBLIOGRAFICAS}

1. BAFFES; T. G. et al - Post operatives infections in 1136 consecutive cardiac operations. Surgery, 68: 791, 1970.

2. BANKS; D. C. - Infection from intravenous catheters. Lancet, 1: 443, 1970.

3. BODEY; G. P. - Epidemiological studies of Pseudomonas species in patiente with leukemia. Amer. J. Med. Sci, 260: 82, 1970.

4. BURDE; D. W. \& Whitby, J. L. - Contamination of hospital desinfectante with Pseudomonas species. Brit. Med. J. 2: $153,1967$.
5. HUTZLER; R. U. - Infecçỏes hospitalares. Rev. Hosp. Clin. Fac. Med. S. Paulo, 27: 193, 1972.

6. CONGHINI; G. et al. - Contribution a l'étude de l'infection post-opératoire. Cahiers D'Anesthésiologie, 8: 911, 1972.

7. ANDERSON; L. C. \& HMMMELSBACK; C. K. - The nurse; first line of defense against infections. Hospitals, 41: 84, 1967.

8. LYON; P. - The infection control nurse. Can nurse, 64: 44, 1968.

9. PIERINI; M. A. - Contribuiçāo da enfermeira no controle da contaminação hospitalar. $R B E, 6: 174,1971$. 
MOURA, M.L.P.A. - Aspectos atuals de enfermagem no controle e tratamento de infecç̄o hospitalar. Rev. Bras. Enf.; DF, 29 : 75-84, 1976.

\section{ANEXO I}

Resumo das atividades desenvolvidas na UNDADE DE INTERNAÇAO para controle e tratamento da infecção hospitalar.

Nas Unidades de Internação foram instituidas as rotinas de:

1 - EM RELAÇAO A LIMPEZA DAS UNDDADES:

1.1. limpeza concorrente ou desinfecção de superfícies

1.2. limpeza terminal

1.3. limpeza dos banheiros e dos vasos sanitários

1.4. limpeza das pias e ralos dos banheiros

1.5. limpeza das corredores e hall de circulação

2 - EM RELAÇAO AO MATERIAL DE USO DO PACIENTE

2.1. Limpeza da Unidade do paciente

2.2. Hompeza e desinfecção de comadres, papagaios e bacias

2.3. desinfecção de cobertores

\section{3 - EM RELAÇAO AS TECNICAS DE ENEERMAGEM}

3.1. higienização do paciente - limpeza de cavidades

3.2. técnicas de sondagem vesical e drenagem vesical contínua

3.3. técnicas de curativos

3.4. técnicas de aspiração de secreçōes

3.5. cuidados a serem tomadas com drenos cavitários

\section{4 - EM RELAÇAO AO PACIENTE CONSIDERADO INFECTADO:}

4.1. isolamento do paciente - modos de se proceder a o isolamento

4.2. colheitas de material

4.3. uso do material descartável

4.4. orientaçōes aos funcionários em relação às técnicas de enfermagem

4.5. orientaçōesc aos familliares do paciente e restriçōes de visitantes.

\footnotetext{
ANEXO II

Resumo das atividades desenvolvidas na UNDADE DE TRATAMENTO INTENSIVO para controle e tratamento da infecção hospitalar.

Nesta Unidade foram instituidas rotinas:

1 - EM RELAÇAO A LIMPEZA DA UNIDADE:

1.1. limpeza concorrente ou desinfecção de ambientes

1.2. limpeza terminal

1.3. limpeza dos banheiros e vasos sanitários

1.4. limpeza das pias e ralos dos banheiros

1.5. Limpeza dos corredores e hall de circulação
} 
MOURA, M.L.P.A. - Aspectos atuais de enfermagem no controle e tratamento de infeç̧āo hospitalar. Rev. Bras. Enf.; DF, 29 : 75-84, 1976.

2 - EM RELAÇAOO AOS EQUIPAMENTOS

2.1. limpeza e desinfecção de respiradores, ventiladores e aspiradores

2.2. limpeza e desinfecção das conexōes dos equipamentos

2.3. limpeza e desinfecção d o material para entubação endotraqueal

3 - EM RELAÇAO AO MATERIAL DE USO DO PACIENTE

3.1. limpeza da Unidade do paciente

3.2. limpeza e desinfecção de comadres, papagaios e bacias

3.3. desinfecção de cobertores

\section{4 - EM RELAÇAO AS TECNICAS DE ENFERMAGEM}

4.1. higienização do paciente - limpeza de cavidades

4.2. técnicas de sondagem vesical e drenagem vesical contínua

4.3. técnicas de curativos

4.4. técnicas de aspiração de secreção

4.5. cuidados a serem tomados com o paciente traqueostomizado

4.6. cuidados a serem tomados com os drenos cavitários dos pacientes

4.7. cuidados a serem tomados com as cateterizaçōes de velas e artérias

5 - EM RELAÇÃO AO PACIENTE INFECTADO

5.1. isolamento do paciente

5.2. colheitas de material

5.3. uso de material descartável

5.4. orientaçōes aos funcionários em relação às técnicas de enfermagem

5.5. problemas da roupa utilizada no isolamento

\section{6 - EM RELAÇAO AO PESSOAL QUE TRABALHA NA UNIDADE DE} TRATAMENTO INTENSIVO

6.1. exame médico periódico com colheita de material de oro-faringe e cultura de fezes - coprocultura

6.2. higienização rigorosa das mãos

6.3. uso de uniforme privativo pelo pessoal da Unidade

\section{ANEXO III}

Resumo das atividades desenvolvidas na UNIDADE DE BERCARIOS para controle e tratamento da infecção hospitalar.

Nesta Unidade foram instituídas rotinas:

1 - EM RELAÇAO A LIMPEZA DA UNIDADE:

1.1. limpeza concorrente ou desinfecção de ambiente

1.2. limpeza terminal

1.3. limpeza das pias

1.4. limpeza dos corredores e hall de circulação 
MOURA, M.L.P.A. - Aspectos atuais de enfermagem no controle e tratamento de infeç̧āo hospitalar. Rev. Bras. Enf.; DF, 29 : 75-84, 1976.

\section{2 - EM RELAÇAO AOS EQUIPAMENTOS}

2.1. limpeza e desinfecção das incubadoras

2.2. limpeza e desinfecção dos berços aquecidos

2.3. limpeza e desinfecção dos respiradores, ventiladores e aspiradores

2.4. limpeza e desinfecção do material para entubação endotraqueal

\section{3 - EM RELAÇAO AO MATERIAL UTILIZADO PELOS RECEM-NASCIDOS}

3.1. limpeza dos berços

3.2. Límpeza e desinfecção dos termômetros utilizados pelos recémnascidos

3.3. uso de material descartável

\section{4 - EM RELAÇÃO AS TECNICAS DE ENEERMAGEM}

4.1. higienização do recém-nascido - limpeza das cavidades - curativo umbelical

4.2. técnicas de aspiração de secreção

4.3. cuidados a serem tomados na adminstração de mamadeiras

4.4. cuidados a serem tomados com as cateterizaçōes de artéria ou veia umbelical

4.5. uso de material descartável

5 - EM RELAÇÃo aO PESSOAL QUE TRABALHA NA UNIDAdE DE BERÇARIOS:

5.1. exame médico periódico com colheita de material de oro-faringe e cultura de fezes - coprocultura

5.2. higienização rigorosa das mãos

5.3. uso de uniforme privativo pelo pessoal da Unidade

\section{ANEXO IV}

Resumo das atividades desenvolvidas nas UNIDADES DE CENTRO CIRURGICO e CENTRO OBSTETRICO para controle e tratamento da infecção hospitalar.

Nestas Unidades foram instituídas rotinas de:

1 - EM RELAÇÃO A LIMPEZA DO AMBIENTE:

1.1. limpeza concorrente ou desinfecção de superfícies

1.2. limpeza terminal

1.3. limpeza de sala contaminada

1.4. cuidados a serem tomados com a roupa da sala

1.5. cuidados a serem tomados com o lixo da sala

1.6. cuidados a serem tomados com os lavabos 
MOURA, M.L.P.A. - Aspectos atuais de enfermagem no controle e tratamento de infecçāo hospitalar. Rev. Bras. Enf.; DF, 29 : 75-84, 1976.

\section{2 - EM RELAÇÃO AOS EQUIPAMENTOS}

2.1. limpeza e desinfecção de ventiladores e aspiradores

2.2. limpeza e desinfecção das conexões dos equipamentos

2.3. limpeza e desinfecção do material de anestesia.

2.4. limpeza e desinfeç̧ão do sistema de ar condicionado

\section{3 - EM RELAÇÃO AO PESSOAL QUE TRABALHA NA UNIDADE:}

3.1. exame médico periódico com colheita de material de oro-faringe

3.2. rotina de degermação das mãos da equipe cirúrgica - uso de produto químico apropriado

3.3. uso de uniforme privativo pelo pessoal que entra nestas Unidades

\section{ANEXO V}

Resumo das atividades desenvolvidas na UNIDADE DO CENTRO DE MATERIAL E ESTERILIZAÇĀO para controle da infecção hospitalar.

\section{1 - EM RELAÇAO A LIMPEZA DA UNIDADE}

1.1. limpeza concorrente ou desinfecção de superfícies

1.2. limpeza terminal

2 - EM RELAÇAO AO MATERIAL

2.1. limpeza adequada do material a ser preparado

2.2. preparo do material

2.3. esterilização do material

2.4. guarda do material

\section{3 - EM RELAÇAOO AO EQUIPAMENTO}

3.1. rotinas de manejo dos autoclaves, estufas

3.2. rotinas de esterilização do material de superfície

3.3. rotinas de esterilização do material de densidade

3.4. rotinas de esterilização do material ótico e elétrico

\section{4 - EM RELAÇAOO AO USO DE PRODUTOS QUIMICOS}

4.1. rotinas de uso de produto químico como esterilizante químico - modo de usar

4.2. rotinos de uso de produto químico como desinfetante - modo de usar 
MOURA, M.L.P.A. - Aspectos atuais de enfermagem no controle e tratamento de infecçāo hospitalar. Rev. Bras. Enf.; DF, 29 : 75-84, 1976.

\section{5 - EM RELAÇÃO AOS TESTES DE ESTERIIZAÇÃO}

5.1. rotinas para teste de esterilização de material de densidade

5.2. rotinas para teste de esterilização de material de superfície

5.3. rotinas para teste de esterilização com calor seco

5.4. rotinas para teste de esterilização pela estufa de formalina

5.5. rotinas para teste de esterilização pelos produtos químicos - esterilização química a frio.

5.6. rotinas para teste da limpeza e desinfecção dos ambientes.

\section{ANEXO VI \\ FICHA DE REGISTRO - CONTROLE DA INFECÇAO HOSPITALAR}

Nome do paciente:

Idade:

cor:

sexo:

n. ${ }^{\circ}$ registro:

Categoria: quarto:

leito:

Data da internação:

Data da operação:

Data do aparecimento da infecção:

Diagnóstico provisório:

Operação realizada:

Antibióticos:

início:

Corticóide:

início:

RESUMO:

TECNICAS DE ENFERMAGEM EFETUADAS E QUE CONCORRERIAM PARA O APARECIMENTO DA INFECÇAO

- Anotar o tipo de técnicas - data da sua execução e se possível o nome do funcionário.

Observaçōes:

Data:

Assinatura. 